\title{
Estrus induction in the non-breeding season is not associated with hydrometra in
}

\section{dairy goats}

\author{
A indução de estro na contra-estação reprodutiva não está associadla à ocorrência de hidrometra \\ em cabras leiteiras \\ La inducción del celo en la estación de anestro no está asociada con la hidrómetra en cabras
} lecheras

\author{
Ana Lucia Rosa e Silva Maia \\ ORCID: https://orcid.org/0000-0001-6875-1730 \\ Universidade Federal Fluminense, Brazil \\ E-mail: maia.analucia@gmail.com \\ Joanna Maria Gonçalves de Souza-Fabjan \\ ORCID: https://orcid.org/0000-0002-4872-1718 \\ Universidade Federal Fluminense, Brazil \\ E-mail: joannavet@gmail.com \\ Paulo Sergio Cerqueira Rangel \\ ORCID: https://orcid.org/0000-0003-3956-9408 \\ Universidade do Grande Rio, Brazil \\ E-mail: paulorangel1102@gmail.com \\ Luana Rangel Côrtes \\ ORCID: https://orcid.org/0000-0003-2731-0060 \\ Universidade Federal Fluminense, Brazil \\ E-mail: luana_rcortes@hotmail.com \\ Maria Emilia Franco Oliveira \\ ORCID: https://orcid.org/0000-0002-7730-290X \\ Universidade Estadual Paulista, Brazil \\ E-mail: m_emiliafraoli@yahoo.com.br \\ Jeferson Ferreira da Fonseca \\ ORCID: https://orcid.org/0000-0001-8028-3984 \\ Embrapa Caprinos e Ovinos, Brazil \\ E-mail: jeferson.fonseca@embrapa.br
}

\begin{abstract}
This study aimed to compare the prevalence of hydrometra (HD) at the end of the reproductive season in goats subjected (HORM and LIGHT) or not (Control-HORM and Control-LIGHT) to estrus induction by either hormonal protocol or light program, respectively, in the non-breeding season. HORM-goats received intravaginal sponges (six days) associated with cloprostenol plus eCG $24 \mathrm{~h}$ before sponge removal while LIGHT-goats were submitted to $16 \mathrm{~h}$ of light and $8 \mathrm{~h}$ of darkness for 60 days. Pregnant goats from both groups gave birth at the early reproductive season and were evaluated by transrectal ultrasound $\sim 45$ days after the end of the season. The control goats (Control-HORM and Control-LIGHT) were also examined. There was no difference in the prevalence of HD between goats from HORM $(8 / 31 ; 25.8 \%)$ compared to Control-HORM $(4 / 26 ; 15.4 \%)$, or LIGHT $(9 / 54 ; 16.7 \%)$ compared to ControlLIGHT $(7 / 51 ; 13.7 \%)$, as well as between HORM and LIGHT groups. In conclusion, estrus induction with both hormonal and light protocols is not associated with the development of HD in dairy goats.
\end{abstract}

Keywords: Anestrus; Pseudopregnancy; Reproductive seasonality; Ultrasonography.

\section{Resumo}

Este estudo teve como objetivo comparar a prevalência de hidrometra (HD) no final da estação de acasalamento em cabras submetidas (HORM e LUZ) ou não (Controle-HORM e Controle-LUZ) à indução de estro na contra-estação reprodutiva por protocolo hormonal ou programa de luz, respectivamente. As cabras do grupo HORM receberam esponjas intravaginais por seis dias, associadas à aplicação de cloprostenol e eCG 24 h antes da retirada das esponjas. As cabras do grupo LUZ foram submetidas a $16 \mathrm{~h}$ de luz e $8 \mathrm{~h}$ de escuridão por 60 dias. $\mathrm{O}$ parto das cabras de ambos os grupos ocorreu no início da estação de acasalamento e estas foram avaliadas por ultrassonografia transretal $\sim 45$ dias após o final da estação. As cabras controle (Controle-HORM e Controle-LUZ) também foram examinadas. Não houve diferença na prevalência de HD entre o grupo HORM $(8 / 31 ; 25,8 \%)$ em comparação com Controle-HORM $(4 / 26 ; 15,4 \%)$, ou LUZ $(9 / 54 ; 16,7 \%)$ em comparação com Controle-LUZ $(7 / 51 ; 13,7 \%)$, assim como entre os grupos 
HORM e LUZ. Em conclusão, a indução de estro na contra-estação reprodutiva com protocolo hormonal e programa de luz não está associada ao desenvolvimento da HD em cabras leiteiras.

Palavras-chave: Anestro; Pseudogestação; Sazonalidade reprodutiva; Ultrassonografia.

\section{Resumen}

Este estudio tuvo como objetivo comparar la prevalencia de hidrometra (HD) al final de la estación reproductiva en cabras sometidas (HORM y LUZ) o no (Control-HORM y Control-LUZ) a la inducción del celo durante el anestro estacional por protocolo hormonal o programa de luz, respectivamente. Las cabras del grupo HORM recibieron esponjas intravaginales por seis días asociadas con la aplicación de cloprostenol y de eCG 24 h antes de la retirada de las esponjas. Las cabras del grupo LUZ fueron sometidas a 16 h de luz y 8 h de oscuridad durante 60 días. El parto de las cabras de ambos os grupos ocurrió al comienzo de la estación reproductiva y estos fueron evaluados por ultrasonografía transrectal $\sim 45$ días después del final de la estación. También se examinaron cabras de control (Control-HORM y Control-LUZ). No hubo diferencia en la prevalencia de HD entre el grupo HORM (8/31; 25,8\%) en comparación con el Control-HORM (4/26; 15,4\%) o de LUZ (9/54; 16,7\%) en comparación con el Control-LUZ $(7 / 51 ; 13,7 \%)$, así como entre los grupos HORM y LUZ. En conclusión, la inducción del celo durante el anestro estacional con protocolo hormonal y programa de luz no se asocia con el desarrollo de HD en cabras lecheras.

Palabras clave: Anestro; Pseudopreñez; Estacionalidad reproductiva; Ultrasonid.

\section{Introduction}

Over the years, wild small ruminants have adapted their reproductive activity to a few months of the year to ensure the supply of food and favorable temperature for the birth and growth of their offspring (reviewed by Gómez-Brunet et al., 2012). Thus, in commercial dairy goat systems, strategies to induce estrus in the non-breeding season became indispensable to guarantee the milk production during the entire year. Methods to induce estrus involve mainly the use of hormonal protocols and artificial light programs. However, both may be related to the occurrence of hydrometra (HD) (Duquesnel et al., 1992; Wittek et al., 1997; Batista et al., 2001; Netto et al., 2020). This disease has been associated with a decrease in reproductive efficiency in dairy goats, however, the exact cause of the disease is not elucidated yet (Maia et al., 2018; Menzies 2019).

Regardless of the method used to circumvent the seasonality, the goats that become pregnant in the non-breeding season will give birth at the beginning of the subsequent reproductive season. Despite all the physiological demands of the initial stage of lactation, about 28 days after parturition the process of uterine involution has finished (Greyling \& Niekerk, 1991). Thus, authors reported that kidding in the reproductive season leads to a shorter postpartum anestrus ( 50 days) (Delgadillo et al., 1998). However, although they would be able to become pregnant again soon after, for logistic/commercial reasons, they are usually not subjected to mating, and the goats will end the reproductive season still non-pregnant, different from what would be naturally expected.

We hypothesize that HD occurs regardless of the strategy used for estrus induction, and that reaching the end of the breeding season without being pregnant may make the goats susceptible to the development HD. Thus, this study compared the prevalence of $\mathrm{HD}$ at the end of the reproductive season in goats subjected to estrus induction (HORM and LIGHT) or not (Control-HORM and Control-LIGHT) in the non-breeding season.

\section{Materials and Methods}

\subsection{Ethics approval}

The study was approved by the Animal Care Committee of the Universidade Federal Fluminense (\#678/2015) and it was conducted under the ethical principles of the Conselho Nacional de Controle de Experimentação Animal (CONCEA; National Council for Control of Animal Experimentation). This study also followed the guidelines of the Animal Research: Reporting of In Vivo Experiments (ARRIVE; Percie du Sert et al., 2020). 


\subsection{Location, animals, and estrus induction}

In order to obtain data from different protocols of estrus induction, the study was performed in two dairy goat farms (Herds 1 and 2) in the Minas Gerais State, Brazil. Apart from reproductive management, the two herds of Saanen goats had similar health and nutritional management. Goats were kept in an intensive production system, confined in group pens, and fed with corn silage. A balanced concentrate supplement was provided according to each category (National Research Council, 2007). Mineralized salt and fresh water were available ad libitum.

In Herd 1, goats $(n=57)$ were allocated in the following groups: 1$)$ HORM had goats $(n=31$, pluriparous $)$ aged $3.1 \pm 0.2$ years and 3.2 \pm 0.1 of body condition score (BCS, mean \pm SEM); 2) Control-HORM had goats ( $n=26$, being 10 nulliparous, 5 primiparous and 11 pluriparous) aged $2.5 \pm 0.3$ years and $3.4 \pm 0.1$ of BCS.

HORM goats had estrus induced in the non-breeding season with intravaginal sponges containing $60 \mathrm{mg}$ of medroxyprogesterone acetate (Progespon ${ }^{\circledR}$, Zoetis, Campinas, Brazil) for six days, associated with i.m. administration of $37.5 \mu \mathrm{g}$ of cloprostenol (Ciosin ${ }^{\circledR}$, MSD Saúde Animal, São Paulo, Brazil) plus 300 IU of eCG (Novormon 5000 ${ }^{\circledR}$, Zoetis, Campinas, Brazil), both $24 \mathrm{~h}$ before sponge removal (Figure 1).

Figure 1. Schematic representation of the procedures for estrus induction by hormonal protocol and light program during the non-breeding season in dairy goats. Time of parturition and ultrasound evaluation was also detailed.

\begin{tabular}{|c|c|c|c|}
\hline & Non-breeding season & \multicolumn{2}{c}{ Reproductive season } \\
\hline June & October/November & March/April
\end{tabular}

\section{Hormonal protocol}

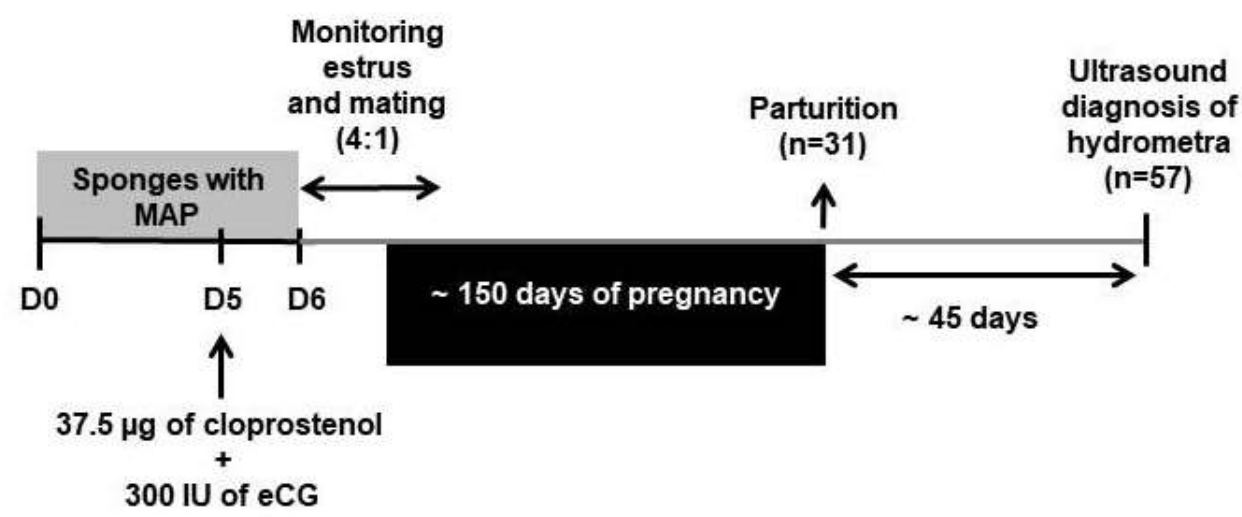

\section{Light program}

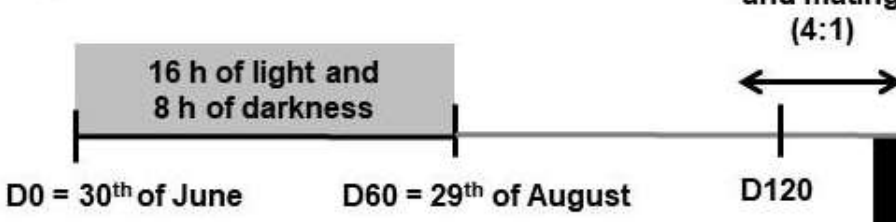

Monitoring

estrus

and mating

(4:1)

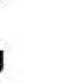

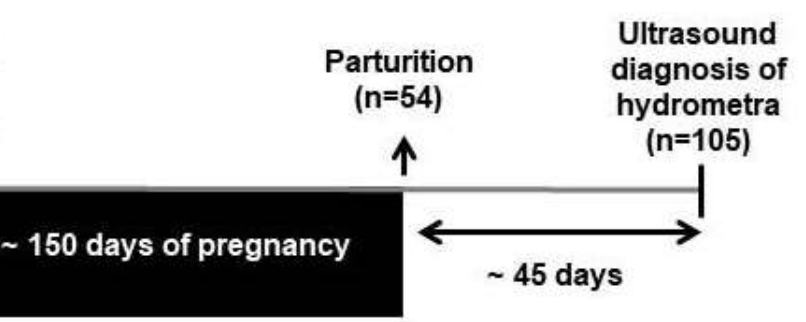

Legend: eCG: equine chorionic gonadotropin; MAP: medroxyprogesterone acetate.

Source: Authors (2021). 
In Herd 2, goats $(n=105)$ were allocated in the following groups: 1) LIGHT had goats ( $n=54$, pluriparous) aged $3.2 \pm 0.2$ years and $2.9 \pm 0.1$ of BCS; 2 ) Control-LIGHT had goats ( $n=51$, being 9 nulliparous, 6 primiparous and 36 pluriparous) aged 2.6 \pm 0.2 years old and $3.0 \pm 0.1$ of BCS.

LIGHT goats had estrus induced by a light program. For this purpose, the goats were confined in the same barn and were submitted to $16 \mathrm{~h}$ of light and $8 \mathrm{~h}$ of darkness for 60 days (from 30th of June to 29th of August). An analogical timer device was regulated to turn the light (200 lux) of the barn on from 04:00 to 08:00 h and 16:00 to 20:00 h. About 60 days from the end of this program, the goats began to present estrus (Figure 1).

After sponge removal and 115 days of the onset of the light program, goats from HORM and LIGHT, respectively, had their estrus monitored twice daily and were mated with fertile bucks. Their parturition occurred $\sim 150$ days, in early reproductive season. During this season, these goats were not mated again.

Control-HORM and Control-LIGHT goats were not induced to estrus in the non-breeding season. These groups were either mated or not in reproductive season, but reached its end without pregnancy, like the HORM and LIGHT goats.

\subsection{Ultrasound exams}

Transrectal ultrasonography (Mindray ${ }^{\circledR}$ DP330-Vet, Shenzhen, China) was performed (according to Maia et al., 2018) $\sim 45$ days after the end of the reproductive season in all goats. During the exam, the following conditions were evaluated: HD, pregnancy (+) and (-), or with any reproductive disorder other than HD (i.e. follicular or luteal cyst, fetal loss, hydrosalpinx). Only the goats diagnosed with HD and pregnancy (-) took part of the study.

\subsection{Statistics}

Statistical analysis was performed using statistical software (BioEstat 5.3, Belém, Brazil). Lilliefors test was used to verify normality. Non-parametric data were analyzed by Mann-Whitney test. Frequencies were assessed by Chi-square or Fisher's exact test. Differences were considered to exist when $P<0.05$.

\section{Results}

The prevalence of HD in the goats according to their group and parity order is presented in Table 1.

Table 1. Prevalence of hydrometra $(\%)$ at the end of the reproductive season ( 45 days after kidding), in dairy goats submitted (HORM and LIGHT) or not (Control-HORM and Control-LIGHT) to estrus induction by hormonal protocol or light program, respectively, in the non-breeding season

\begin{tabular}{|c|c|c|c|c|c|c|c|c|}
\hline & HORM & Control-HORM & $P$ value ${ }^{*}$ & $P$ value ${ }^{* *}$ & LIGHT & Control-LIGHT & $P$ value ${ }^{*}$ & $P$ value ${ }^{* *}$ \\
\hline Nulliparous (\%) & - & $10.0(1 / 10)$ & 1 & - & - & $0(0 / 9)$ & 1 & 1 \\
\hline Primiparous (\%) & - & $20.0(1 / 5)$ & 1 & - & - & $16.7(1 / 6)$ & 1 & 1 \\
\hline Pluriparous (\%) & $25.8(8 / 31)$ & $18.2(2 / 11)$ & 0.7 & 0.4 & $16.7(9 / 54)$ & $16.7(6 / 36)$ & 1 & 1 \\
\hline Total/group (\%) & $25.8(8 / 31)$ & $15.4(4 / 26)$ & 0.5 & 0.4 & $16.7(9 / 54)$ & $13.7(7 / 51)$ & 0.9 & 1 \\
\hline Total/herd (\%) & \multicolumn{2}{|c|}{$21.1(12 / 57)$} & & & \multicolumn{2}{|c|}{$15.2(16 / 105)$} & 0.5 & \\
\hline
\end{tabular}


$P$ value*: within rows, comparison between the groups submitted or not, respectively, to estrus induction by hormonal (HORM vs. ControlHORM) or light protocols (LIGHT vs Control-LIGHT) (Fisher exact test or Chi-squared test).

$P$ value ${ }^{* *}$ within rows, comparison between the type of estrus induction (HORM vs. LIGHT) or control (Control-HORM vs Control-LIGHT) (Fisher exact test or Chi-squared test).

Source: Authors (2021).

Observing the results presented in Table 1 , it can be verified that there was no difference $(P>0.05)$ in the prevalence of HD between goats from HORM $(8 / 31 ; 25.8 \%)$ compared to Control-HORM (4/26; 15.4\%), or LIGHT (9/54; 16.7\%) compared to Control-LIGHT $(7 / 51 ; 13.7 \%)$, as well as between HORM and LIGHT groups. Moreover, the disease affected similarly $(P>0.05)$ pluriparous goats $(25 / 132,18.9 \%)$ when compared with nulliparous + primiparous $(3 / 30,10 \%)$.

\section{Discussion}

In the present study, the hypothesis that the strategy of estrus induction is not the cause of hydrometra was confirmed, as there was no difference in the prevalence of goats affected by HD compared to those submitted to either HORM or LIGHT protocols. Different studies reported the occurrence of HD due to hormonal protocols (Duquesnel et al., 1992; Wittek et al., 1997). In a cross-sectional study with 1,604 goats, our group suggested that hormonal estrus induction could be considered a risk factor to the prevalence of HD when compared to light regimens. However, the survey revealed that the farmers did not have a standard in the use of such hormonal protocols (Maia et al., 2019), which may contribute to the hormonal imbalance leading to the HD development. Furthermore, HD was also reported in a frequency of $9 \%$ from herds situated near the Equator line (latitude $8^{\circ} \mathrm{S}$ ) where there is no seasonal anestrus and induction of estrus is not performed (Moraes et al., 2007).

In the present study, the prevalence of HD was similar among all goats regardless of estrus induction and parturition at the beginning of the reproductive season. Authors reported that HD is higher in goats that give birth during the reproductive season (Duquesnel et al., 1992). It was verified that the selection of goats with the genetic ability to kid out of season presented a moderately positive correlation with the occurrence of HD (Desire et al., 2018). These authors also observed that if the first parturition occurs far from the natural kidding season (spring) the goats are more susceptible to develop HD again in their next breeding. Indeed, HD was also diagnosed during the reproductive season after spontaneous estrus behavior and hormonal induced estrus (Hesselink, 1993). Thus, we can speculate that goats that take a long time to get pregnant or need hormonal estrus induction during the reproductive season may present some kind of inadequate behavior or reproductive disorder (not visible by ultrasonography). In this context, nulliparous goats at the onset of sexual activity, and females with subordinated behavior that show silent or delayed estrus (and failure in the initial pregnancy) may reach the end of the reproductive season without mating and pregnancy. Thus, we can speculate that goats which ovulation occurs at the end of the reproductive season, may maintain luteal activity even if a pregnancy does not occur. Probably, in this period some goats present a disturbance in luteolytic stimuli leading to CL persistence and HD development (Garverick et al., 1992; Moraes et al., 2007). This leads us to emphasize the need for ultrasound evaluation not only for the pregnancy diagnosis but also to assess whether the goats can be mated or if they need any kind of treatment before the onset of the season.

\section{Conclusion}

In conclusion, estrus induction with both hormonal and light protocols is not associated with the development of HD in dairy goats. This information highlights that people involved in dairy goats breeding have to be aware of the reproductive history of females, especially those who reach the end of the mating season without being pregnant. With the ultrasonographic evaluation, it is possible to check if the females had a fetal loss, HD, or any other disorder that could impair their reproductive 
activity. As HD still causes economic loss for dairy goat producers, more studies must be carried out to elucidate the causes of this reproductive disorder.

\section{Acknowledgments}

The authors thank the farmers involved for providing animals and animal housing conditions.

\section{Funding information}

The authors thank to EMBRAPA (Project: 20.19.01.004.00.03.001), CNPq (Projects: 479826/2013-7 and 314952/2018-7) and FAPEMIG (Project: CVZ-PPM 00201-17) for financial support. ALRSM and JMGS-F are fellows of FAPERJ, MEFO and JMGS-F of CNPq, JFF of FAPEMIG and CNPq.

\section{References}

Batista, M., Medina, J., Calero, R., Gonzalez, F., Quesada, E. \& Gracia, A. (2001). Incidence and treatment of hydrometra in Canary Island goats. Veterinary Record, 149, 329-330.

Delgadillo, J. A., Flores, J. A., Villarreal, O., Flores, M. J., Hoyos, G., Chemineau, P. \& Malpaux, B. (1998). Length of postpartum anestrus in goats in subtropical Mexico: effect of season of parturition and duration of nursing. Theriogenology, 49(6), 1209-1218.

Desire, S., Mucha, S., Coffey, M., Mrode, R., Broadbent, J. \& Conington, J. (2018). Pseudopregnancy and aseasonal breeding in dairy goats: Genetic basis of fertility and impact on lifetime productivity. Animal, 12(9), 1799-1806.

Duquesnel, R., Parisot, D., Pirot, G., Mialot, J. P., Saboureau, L., Étienne, P., Delaval, J., Guéraud, J. M., Prengere, E., Montigny, G., Guerrault, P., Perrin, G., Humblot, P., Fontaubert, Y. \& Chemineau, P. (1992). La pseudogestation chez la chèvre. Annales de Zootechnie, 41, 407-415.

Garverick, H. A., Zollers, W. G. \& Smith, M. F. (1992). Mechanisms associated with corpus luteum lifespan in animals having normal or subnormal luteal function. Animal Reproduction Science, 28, 111- 124

Gómez-Brunet, A., Santiago-Moreno, J., Toledano-Diaz, A. \& López-Sebastián, A. (2012). Reproductive seasonality and its control in Spanish sheep and goats. Tropical and Subtropical Agroecosystems, 15(sup 1), S47-S70.

Greyling, J. P. C. \& Van Niekerk, C. H. (1991). Macroscopic uterine involution in the post-partum Boer goat. Small Ruminant Research, 4(3), $277-283$.

Hesselink, J.W. (1993). Incidence of hydrometra in dairy goats. Veterinary Record, 132, 110-112.

Maia, A. L. R. S., Brandão, F. Z., Souza-Fabjan, J. M. G., Veiga, M. O., Balaro, M. F. A., Facó, O. \& Fonseca, J. F. (2018). Transrectal ultrasound evaluation in tropical dairy goats: an indispensable tool for the diagnosis of reproductive disorders. Tropical Animal Health and Production, 50(4), 787-792.

Maia, A. L. R. S., Silva, M. R., Brandão, F. Z., Souza-Fabjan, J. M. G., Faria, L. S., Côrtes, L. R., Facó, O. \& Fonseca, J.F. (2019). Epidemiological survey and risk factors associated with hydrometra in dairy goat herds. Small Ruminant Research, 178, 79-84.

Menzies, P. (2019). Pseudopregnancy in goats - an important cause of subfertility. Veterinary Record,184(25), 767-769.

Moraes, E. P. B. X., Santos, M. H. B., Arruda, I. J., Bezerra, F. Q. G., Aguiar Filho, C. R., Neves, J. P., Lima, P. F. \& Oliveira, M. A. L. (2007). Hydrometra and mucometra in goats diagnosed by ultrasound and treated with PGF2 $\alpha$. Medicina Veterinária, 1(1), 33-39.

National Research Council - NRC (2007). Nutrient Requirements of Goats, (The National Academies Press, Washington, D.C.).

Netto, M. M., Balaro, M. F. A., Cosentino, I. O., Espírito Santo, C. G., Oliveira, R. V., Souza-Fabjan, J. M. G., Brandão, F. Z., \& Fonseca, J. F. (2020). Use of two cloprostenol administrations 11.5 days apart efficiently synchronizes oestrus in photostimulated multiparous dairy goats in the non-breeding season. Reproduction in Domestic Animals, 55, 965-973.

Percie du Sert, N., Hurst, V., Ahluwalia, A., Alam, S., Avey, M. T., Baker, M., Browne, W. J., Clark, A., Cuthill, I. C., Dirnagl, U., Emerson, M., Garner, P., Holgate, S. T., Howells, D. W., Karp, N. A., Lazic, S. E., Lidster, K., Mac Callum, C. J., Macleod, M., Pearl, E. J., Petersen, O. H., Rawle, F., Reynolds, P., Rooney, K., Sena, E. S., Silberberg, S. D., Steckler, T. \& Würbel, H. (2020). The ARRIVE guidelines 2.0: Updated guidelines for reporting animal research. PLoS Biology, 18(7): e3000410

Wittek, T., Richter, A., Erices, J. \& Elze, K. (1997). Incidence, diagnosis, therapy and subsequent fertility in goats with hydrometra. Tierarztl Prax Ausg G Grosstiere Nutztiere, 25(6), 576-582 (Abstract in English). 